\title{
Prenatal exposure to organophosphate pesticides and risk-taking behaviors in early adulthood
}

\author{
Sharon K. Sagiv ${ }^{1 *} \mathbb{D}$, Stephen Rauch ${ }^{1}$, Katherine R. Kogut ${ }^{1}$, Carly Hyland ${ }^{1}$, Robert B. Gunier ${ }^{1}$, Ana M. Mora ${ }^{1}$,
} Asa Bradman ${ }^{1,2}$, Julianna Deardorff ${ }^{1}$ and Brenda Eskenazi ${ }^{1}$

\begin{abstract}
Introduction: Previous studies show evidence for associations of prenatal exposure to organophosphate (OP) pesticides with poorer childhood neurodevelopment. As children grow older, poorer cognition, executive function, and school performance can give rise to risk-taking behaviors, including substance abuse, delinquency, and violent acts. We investigated whether prenatal OP exposure was associated with these risk-taking behaviors in adolescence and young adulthood in a Mexican American cohort.
\end{abstract}

Methods: We measured urinary dialkyl phosphates (DAPs), non-specific metabolites of OPs, twice (13 and 26 weeks gestation) in pregnant women recruited in 1999-2000 in the Center for the Health Assessment of Mothers and Children of Salinas (CHAMACOS) study, a birth cohort set in a primarily Latino agricultural community in the Salinas Valley, California. We followed up children throughout their childhood and adolescence; at the 18-year visit, adolescent youth $(n=315)$ completed a computer-based questionnaire which included questions about substance use, risky sexual activity, risky driving, and delinquency and police encounters. We used multivariable models to estimate associations of prenatal total DAPs with these risk-taking behaviors.

Results: The prevalence of risk-taking behaviors in CHAMACOS youth ranged from 8.9\% for smoking or vaping nicotine to $70.2 \%$ for committing a delinquent act. Associations of total prenatal DAPs (geometric mean $=132.4 \mathrm{nmol} / \mathrm{L}$ ) with risk-taking behavior were generally null and imprecise. Isolated findings included a higher risk for smoking or vaping nicotine within the past 30 days (relative risk [RR] per 10-fold increase in prenatal DAPs $=1.89,95 \% \mathrm{Cl}: 1.00$, 3.56) and driving without a license ( $\mathrm{RR}=1.74,95 \% \mathrm{Cl}: 1.25,2.42)$. There were no consistent differences by sex or childhood adversity.

Discussion: We did not find clear or consistent evidence for associations of prenatal OP exposure with risk-taking behaviors in adolescence/early adulthood in the CHAMACOS population. Our small sample size may have prevented us from detecting potentially subtle associations of early life OP exposure with these risk-taking behaviors.

Keywords: Pesticides, Organophosphates, Prenatal exposure, Risky behavior, Substance use, Sexual behavior, Risky driving, Delinquency

\footnotetext{
*Correspondence: sagiv@berkeley.edu

${ }^{1}$ Center for Environmental Research and Community Health (CERCH),

School of Public Health, University of California, 1995 University Avenue, Suite 265, Berkeley, CA 94720, USA

Full list of author information is available at the end of the article
}

\section{Background}

Prospective birth cohort studies have reported adverse neurodevelopment in association with prenatal organophosphate (OP) pesticide exposure [1-12]. In our Center for the Health Assessment of Mothers and Children of original author(s) and the source, provide a link to the Creative Commons licence, and indicate if changes were made. The images or other third party material in this article are included in the article's Creative Commons licence, unless indicated otherwise in a credit line to the material. If material is not included in the article's Creative Commons licence and your intended use is not permitted by statutory regulation or exceeds the permitted use, you will need to obtain permission directly from the copyright holder. To view a copy of this licence, visit http://creativecommons.org/licenses/by/4.0/. The Creative Commons Public Domain Dedication waiver (http://creativeco mmons.org/publicdomain/zero/1.0/) applies to the data made available in this article, unless otherwise stated in a credit line to the data. 
Salinas (CHAMACOS) study, a birth cohort set in a community living in proximity to agricultural fields in Salinas Valley, California, we have shown associations of prenatal urinary OP metabolites, a biomarker of exposure, with poorer neurodevelopment in childhood and early adolescence (through age 14years), including poorer cognitive function [2], more hyperactive and inattentive behaviors [4], and poorer executive function [11] and social cognition [5].

Evidence suggests that poorer neurodevelopment in childhood may predict long-term problems, such as substance abuse, delinquency, violence, and other risktaking behaviors in adolescence and early adulthood. For example, studies have observed that hyperactivity, impulsivity, and risk-taking behaviors at age 10 predict delinquency at ages 12-13 [13] and violence at ages 14 and 16 [14]. Children with attention deficit hyperactivity disorder (ADHD) are also more likely to engage in property theft, disorderly conduct, assault, and possession of a concealed weapon [15]; to be arrested [16], including for violent crimes $[17,18]$; and to report alcohol, tobacco and illicit drug use $[19,20]$. Furthermore, studies have reported that delinquent adolescents and criminal adult offenders have IQs averaging 6 to 11 points lower than those without a history of delinquency and criminality $[21,22]$.

Scientific literature suggests that early life exposure to lead, air pollution, and tobacco smoke may increase the risk of delinquent and criminal behavior in adolescence and early adulthood, even after controlling for socioeconomic status [23-35]. We recently reported mostly null associations of prenatal and childhood OP metabolite concentrations with juvenile delinquency up to age 16 years in CHAMACOS [36]. In the current study, we investigated associations of prenatal urinary OP metabolite concentrations with a broader group of risk-taking behaviors in CHAMACOS young adults up to age 18 years, including substance use, risky sexual activity, risky driving, and delinquency and police encounters.

\section{Methods}

\section{Study sample}

We recruited pregnant women from community clinics in California's Salinas Valley between October 1999 and October 2000. These clinics primarily serve the Salinas Valley's population of Mexican-origin agricultural workers and their families. Women were eligible to participate if they were $\geq 18$ years old, spoke Spanish or English, qualified for low-income health insurance, were $<20$ weeks gestation, and were planning to deliver at a local hospital. A total of 601 women were enrolled in the study, of whom 537 were followed through the birth of a live-born infant. Mother-child dyads were followed up every 1-2 years from 6 months to 18 years of age. A total of 317 young adults completed the protocol through age 18, of whom 315 (52\% of the initial cohort) had mothers who had provided a urine sample prior to delivery; these participants comprised the study population included in the current analysis.

Written informed consent was obtained from mothers upon enrollment and follow up; children provided verbal assent starting at age 7 , written assent starting at age 12 , and full written consent at age 18. All activities were approved by the University of California, Berkeley Office for the Protection of Human Subjects.

\section{OP pesticide exposure assessment}

Detailed descriptions of urine collection, analysis, and quality control procedures for dialkyl phosphates (DAPs), non-specific metabolites of OP exposure, have been presented elsewhere [37]. Briefly, urine samples were obtained from the mothers at approximately 13 weeks and 26 weeks gestation. Samples were aliquoted and stored at $-80^{\circ} \mathrm{C}$ and then shipped on dry ice to the Centers for Disease Control and Prevention for analysis using gas chromatography-tandem mass spectrometry [38]. We quantified 6 dialkyl phosphate (DAP) metabolites, including three dimethylphosphate (DM) metabolites (dimethylphosphate, dimethyldithiophosphate, dimethylthiophosphate) and three diethylphosphate (DE) metabolites (diethylphosphate, diethyldithiophosphate, diethylthiophosphate). We summed their molar concentrations $(\mathrm{nmol} / \mathrm{L})$ to estimate total DAP metabolite concentrations. In CHAMACOS, DM metabolite concentrations greatly exceeded DE concentrations and were very similar to total DAP concentrations [37]. We therefore conducted analyses with only total DAPs.

We imputed metabolite values below the limit of detection using random imputation based on a log-normal probability distribution [37]. To correct for urine dilution, we corrected total DAP concentrations for specific gravity in all analyses [39]. We measured specific gravity using a refractometer (National Instrument Company, Inc., Baltimore, MD) calibrated with deionized water at room temperature.

\section{Assessment of risk-taking behaviors}

At the 18-year study visit, adolescent participants completed a computer-based questionnaire that included questions about lifetime risk-taking behaviors. Adolescents were assured that their responses would be kept confidential to encourage candor in answering sensitive questions. We selected risk-taking behaviors across the following four domains: 1) substance use, 2) sexual activity, 3) driving, and 4) delinquency and police encounters. 


\section{Substance use}

Questions on substance use were from the Monitoring the Future Survey (https://www.drugabuse.gov/drugtopics/trends-statistics/monitoring-future), and included items on alcohol, marijuana, and tobacco (smoked, vaped, or in other forms). From these data, we derived the following three dichotomous outcomes: 1) having been very drunk in the past 30 days; 2) smoking or vaping nicotine in the past 30 days; and 3) smoking or vaping marijuana in the past 30 days.

\section{Sexual activity}

Questions on sexual activity were from the Youth Risk Behavior Surveillance (YRBS) Survey [40], the National Institutes of Mental Health Risk Prevention Survey [41], and a Sexual Behavior Survey [42]. From these scales, we derived two dichotomous outcomes: 1) initiating sex before age 16 years; and 2) not always using a condom during vaginal sex.

\section{Driving}

Data on risky driving practices were drawn from the YRBS [40] and the Driver Behavior Rating Scale [43]. From these surveys we derived three dichotomous variables: 1) driving without a seat belt as the driver or passenger; 2) texting or looking at a mobile phone while driving; and 3) driving without a license.

\section{Delinquency and police encounters}

We created a checklist of delinquent or criminal behaviors which we adapted from the Self-Reported Delinquency and Self-Reported Behavior scales [44-46]. The checklist included items ranging from minor delinquency (e.g., lying about age to see a movie) to serious felony offences (e.g., arson, auto theft). Additional file 1 includes a full list of these delinquent acts. For each act, participants were asked to indicate whether they had ever committed the act, and if yes, their age when they first committed the act, and the total number of times they committed the act in their lifetime (1 time, 2-3 times, 4-5 times, or 6 or more times). Participants were also asked to report any instances of being "arrested, stopped, picked up, or questioned by the police" and to provide details on their age, the circumstances, and the outcome of each police encounter [45]. From this checklist, we derived two dichotomous outcomes: 1) committing at least one delinquent act; and 2) having an encounter with the police. We also examined delinquency and police encounters as counts, including: 1) number of different kinds of delinquent acts committed (i.e., a count of the unique types of acts in our delinquency checklist that the youth endorsed); 2) frequency of commission of delinquent acts (i.e., a sum of the number of times any delinquent acts were committed); and 3) number of police encounters. As an example, a youth who reported running away one time, shoplifting six or more times, and no other offenses would have committed two different kinds of delinquent acts with a total frequency of seven or more offenses.

\section{Assessment of adverse childhood experiences}

We administered an adaptation of the Centers for Disease Control and Prevention (CDC) Adverse Childhood Experiences (ACE) survey [47] to young adult participants at the 18-year visit. The ACE survey includes questions about adverse events in the first 18 years of life and has shown good predictive validity [48]. Questions ranged from having enough to eat to physical and sexual abuse (see Additional file 2). Total scores ranged as low as 0 and were capped at 5 .

\section{Covariate assessment}

Study staff collected data on sociodemographic indicators at in-person visits conducted twice during pregnancy (13- and 26-weeks' gestation), shortly following delivery, when children were 6 months, and every $1-2$ years up to child's age 18 years. At the child's 6-month and 9-year visits, mothers were administered the Peabody Picture Vocabulary Test [49], or its Spanish equivalent [50], to assess their receptive language. Mothers were also administered the Center for Epidemiologic Studies Depression Scale (CES-D) at the child's 1, 3, 7, and 9-year visits to assess their depressive symptoms [51]. Finally, mothers completed the Home Observation for the Measurement of the Environment (HOME)-Short Form at the child's 6 months, 1, 2, 3.5, 7, 9, 10.5, and 12-year visits to assess enrichment in the home environment [52].

\section{Statistical analysis}

We corrected DAP metabolite concentrations for specific gravity for each of the two pregnancy (13- and 26-week) urine samples and computed the mean value. We then $\log _{10}$ transformed mean DAP concentrations to reduce the influence of outliers and estimated associations with risk for outcomes across the four domains of risk-taking behaviors (substance use, sexual activity, driving, and delinquency/police encounters) per 10-fold increase in DAP concentrations using multivariable models. For dichotomous outcomes, we used generalized linear models with a log link and Poisson distribution. For count outcomes, we obtained incidence rate ratios using models with a negative binomial distribution to correct for overdispersion. In all cases we produced robust standard errors using the Huber-White sandwich estimator. 
Based on previous studies examining of associations of DAPs with neurodevelopmental outcomes [2, 4, 5, 11 ], we selected the following covariates for inclusion in multivariable models: maternal age at delivery (continuous), education ( $\leq 6$ th grade, 7 th -12 th grade, high school graduate), years spent in the U.S. prior to delivery ( $\leq 5$ years, $>5$ years but non-native, native to U.S.), marital status at enrollment (married or living as married, not married or living as married), and depression $(<16$, $\geq 16$ on the CES-D, assessed at the 9-year visit); HOME $\mathrm{z}$-score at the 6-month visit (continuous); and household poverty status at the time of assessment (at or below poverty level, $>100 \%$ of poverty level). We also included child sex and age at assessment (continuous), which are strongly related to outcomes, enhancing precision of estimates. For missing covariate values, we used the participant's value from another proximal visit when possible and randomly imputed the small number of remaining missing values $(n=1$ missing maternal depression, $n=1$ missing HOME score).

We examined possible effect modification by two different factors: sex (males vs. females) and ACE score, dichotomized as low (0-2) vs. high $(3+)$. In separate models, we included an interaction term between DAP concentrations and each modifier, derived stratum-specific effect estimates, and computed a Wald $p$-value for statistical interaction. Where we found associations of prenatal DAP concentrations with risk-taking behaviors, we used causal inference models [53] to assess mediation by neurodevelopmental outcomes for which we previously reported associations with DAPs, including IQ [2], attention $[4,8]$, and executive function [11].

\section{Results}

As shown in Table 1, a large proportion of mothers in the CHAMACOS cohort (44.8\%) had a $\leq 6$ th grade education at the time of delivery, almost half $(47.6 \%)$ had lived in the U.S. $\leq 5$ years prior to delivery, and most (83.2\%) were married or living as married at that time. At the time of the 18-year visit, the majority of households (59.1\%) were at or below the poverty line. Prenatal total DAP concentrations, averaged over the 13- and 26-week measures, were slightly higher among younger mothers, mothers not born in the U.S., and more well-educated and less impoverished mothers (Table 1). Participants included in the analysis $(n=315)$ differed only slightly from those not included $(n=222)$ as shown in Additional file 3; included participants had mothers who were slightly older and lived in the U.S. longer at the time of delivery and were more likely to be female.

The prevalence of risk-taking behaviors ranged from $8.9 \%$ (smoking or vaping nicotine) to $70.2 \%$ (committing any delinquent act) (Table 2). Risk-taking behaviors, including substance use and risky sex, were most common among youth born to non-U.S. born mothers who were living in the U.S. > 5years at the time of their child's birth (Additional file 4). Substance use, delinquent acts, and police encounters were considerably more common among males than females (Additional file 4).

As shown in Table 2, associations of total prenatal DAPs with risk-taking behaviors were generally null and imprecise, with two exceptions: a 10-fold increase in total prenatal DAP concentrations was associated with a higher risk of smoking or vaping nicotine within the past 30 days (relative risk $[R R]=1.89,95 \% \mathrm{CI}: 1.00,3.56$ ) and driving without a license $(R R=1.74,95 \% \mathrm{CI}: 1.25,2.42)$.

Associations across sex were inconsistent, mostly hovering at the null (Table 2). There was slightly higher risk for smoking or vaping nicotine within the past 30 days with a 10-fold increase in total prenatal DAP concentrations among females $(\mathrm{RR}=2.50,95 \% \mathrm{CI}: 1.10,5.66) \mathrm{vs}$. males $(\mathrm{RR}=1.46,95 \% \mathrm{CI}: 0.56,3.79 ; p$-value for interaction $=0.41$ ). In addition, there was a slightly higher risk for driving without a license with a 10-fold increase in total prenatal DAP concentrations among males $(\mathrm{RR}=2.18,95 \% \mathrm{CI}: 1.35,3.50)$ vs. females $(\mathrm{RR}=1.46$, $95 \%$ CI: 0.93, 2.28; $p$-value for interaction $=0.23)$. Finally, there was a pattern of slightly higher risk associated with prenatal DAP concentrations for delinquent acts and police encounters among males (e.g., for counts of police encounters $\mathrm{IRR}_{\text {males }}=2.10,95 \% \mathrm{CI}: 0.97,4.54$ vs. IRR $_{\text {females }}=1.10,95 \%$ CI: $0.51,2.38 ; p$-value for interaction $=0.24$ ). None of these sex differences were statistically significant and stratum specific estimates were imprecise.

We also found little difference in DAP-risk taking behaviors across low and high ACE scores (Table 3). There was slightly higher risk for smoking/vaping nicotine in the past 30 days in association with DAP concentrations for those with high ACE scores $(\mathrm{RR}=2.49$, 95\% CI: $0.95,6.54)$ vs. those with low ACE scores $(\mathrm{RR}=1.41,95 \% \mathrm{CI}: 0.55,3.60)$, but confidence intervals were wide and the difference was not statistically significant $(p$-value for interaction $=0.43)$. Similar differences were found for counts of police encounters, but were again imprecise $\left(\mathrm{IRR}_{\text {highACEs }}=2.53,95 \% \mathrm{CI}: 1.07\right.$, 6.02 vs. $\mathrm{IRR}_{\text {lowACEs }}=1.39,95 \%$ CI: $0.69,2.83$; $p$-value for interaction $=0.30$ ). The only statistically significant difference associated with prenatal DAP concentrations was for counts of delinquency acts, though in the opposite direction than expected $\left(\mathrm{IRR}_{\text {highACEs }}=0.72,95 \% \mathrm{CI}\right.$ : 0.36 , 1.45 vs. $\mathrm{IRR}_{\text {lowACEs }}=1.76,95 \%$ CI: $1.06,2.92 ; p$-value for interaction $=0.04$ ).

Largely null associations of DAP concentrations with risk-taking behaviors precluded us from examining mediation by neurodevelopmental outcomes. 
Table 1 Sociodemographic and exposure characteristics of youth $(n=315)$ included in analysis: CHAMACOS study population, enrolled 1999-2000 in Salinas Valley, California

\begin{tabular}{|c|c|c|}
\hline Covariate & n (\%) & $\begin{array}{l}\sum \mathrm{DAPs}(\mathrm{nmol} / \mathrm{L}) \\
\mathrm{GM} \pm \mathrm{GSD}\end{array}$ \\
\hline \multicolumn{3}{|l|}{ Maternal age at delivery (years) } \\
\hline $18-24$ & $128(40.6)$ & $145.8 \pm 2.9$ \\
\hline $25-29$ & $107(34.0)$ & $123.9 \pm 2.8$ \\
\hline $30-34$ & $51(16.2)$ & $131.6 \pm 2.3$ \\
\hline $35-45$ & $29(9.2)$ & $112.3 \pm 2.8$ \\
\hline \multicolumn{3}{|l|}{ Maternal education at baseline } \\
\hline$\leq 6$ th grade & $141(44.8)$ & $127.1 \pm 2.9$ \\
\hline 7th-12th grade & $111(35.2)$ & $123.5 \pm 2.6$ \\
\hline High school grad or higher & $63(20.0)$ & $164.2 \pm 2.8$ \\
\hline \multicolumn{3}{|l|}{ Years living in US prior to delivery } \\
\hline$\leq 5$ years & $150(47.6)$ & $134.8 \pm 2.7$ \\
\hline$>5$ years, non-native & $134(42.5)$ & $134.5 \pm 2.8$ \\
\hline Born in US & $31(9.8)$ & $113.4 \pm 2.8$ \\
\hline \multicolumn{3}{|l|}{ Marital status at baseline } \\
\hline Married or living as married & $262(83.2)$ & $130.6 \pm 2.8$ \\
\hline Not married or living as married & $53(16.8)$ & $141.7 \pm 2.4$ \\
\hline \multicolumn{3}{|l|}{ Maternal depression at 9-year visit ( $\geq 16$ on CES-D) } \\
\hline Yes & $81(25.7)$ & $143.7 \pm 2.5$ \\
\hline No & $234(74.3)$ & $128.8 \pm 2.8$ \\
\hline \multicolumn{3}{|l|}{ Young adult's sex } \\
\hline Male & $143(45.4 \%)$ & $140.9 \pm 2.7$ \\
\hline Female & $172(54.6 \%)$ & $125.8 \pm 2.8$ \\
\hline \multicolumn{3}{|l|}{ Household poverty at 18-year visit } \\
\hline At or below poverty & $129(41.0)$ & $119.0 \pm 2.8$ \\
\hline \multirow[t]{2}{*}{$>100 \%$ poverty level } & $186(59.1)$ & $142.6 \pm 2.7$ \\
\hline & GM (GSD) & \\
\hline HOME z-score at 6 months & $0.02(1.06)$ & \\
\hline Young adult's age at 18 -year visit & $18.2(0.3)$ & \\
\hline Total DAP concentrations (nmol/L) & $132.4 \pm 2.7$ & \\
\hline Total DAP concentrations, specific gravity adjusted & $171.5 \pm 2.8$ & \\
\hline
\end{tabular}

\section{Discussion}

We did not find any strong or consistent associations of prenatal OP pesticide exposure with risk-taking behaviors, including substance use, risky sexual activity, risky driving, and delinquency/police encounters among 18-year-old young adults in CHAMACOS. While there were some isolated associations of DAP concentrations with higher risk for smoking/vaping and for driving without a license, the absence of any consistent patterns made these findings less credible. In addition, there were no consistent differences in these associations across potential modifiers, including sex and childhood adversity. The mostly null associations may be due to the number of CHAMACOS study participants with measured prenatal DAP concentrations and 18-year follow-up data $(n=315)$, which may be too small to detect potentially subtle associations of prenatal OP pesticide exposure with risk-taking behaviors.

Previous studies have demonstrated that early life exposure to environmental toxicants can have life-long sequelae, in line with the early origins of disease theory $[54,55]$. For example, early life exposure to lead has been shown to be linked to adverse consequences in adolescence and early adulthood, such as delinquency, substance abuse, and criminality [23-32]. Previous studies have not examined the downstream consequences of early life pesticide exposure, however. Much of the previous epidemiologic literature on OP pesticides has focused on neurodevelopmental outcomes in childhood. We recently reported that prenatal and 
Table 2 Adjusted $^{a}$ relative risk (RR) of risk-taking behaviors reported at 18 years per 10-fold increase in mean prenatal total urinary DAP concentrations (nmol/gL), overall and stratified by sex, in the CHAMACOS study population, enrolled 1999-2000 in Salinas Valley, California

\begin{tabular}{|c|c|c|c|c|c|c|}
\hline Outcome & Total N & N (\%) with outcome & $\operatorname{RR}(95 \% \mathrm{Cl})^{\mathrm{a}}$ & $\begin{array}{l}\text { Males RR } \\
(95 \% \mathrm{CI})^{\mathrm{a}}\end{array}$ & $\begin{array}{l}\text { Females RR } \\
(95 \% \mathrm{Cl})^{\mathrm{a}}\end{array}$ & $\begin{array}{l}p \text {-value for } \\
\text { interaction }\end{array}$ \\
\hline \multicolumn{7}{|l|}{ Substance Use $(\mathrm{Y} / \mathrm{N})^{\mathrm{b}}$} \\
\hline Very drunk in last 30 days & 315 & $30(9.5)$ & $0.96(0.43,2.15)$ & $1.53(0.55,4.25)$ & $0.65(0.20,2.16)$ & 0.27 \\
\hline Smoked/vaped nicotine in last 30 days & 315 & $28(8.9)$ & $1.89(1.00,3.56)$ & $1.46(0.56,3.79)$ & $2.50(1.10,5.66)$ & 0.41 \\
\hline $\begin{array}{l}\text { Smoked/vaped marijuana in the past } \\
\text { last } 30 \text { days }\end{array}$ & 315 & $78(24.8)$ & $1.11(0.71,1.73)$ & $1.26(0.72,2.19)$ & $0.99(0.52,1.89)$ & 0.56 \\
\hline \multicolumn{7}{|l|}{$\operatorname{Sex}(Y / N)^{b}$} \\
\hline Sex before age 16 & 311 & $47(15.1)$ & $1.16(0.64,2.12)$ & $1.91(0.84,4.34)$ & $0.81(0.34,1.92)$ & 0.15 \\
\hline Doesn't always use a condom & 310 & $70(22.6)$ & $0.98(0.63,1.51)$ & $0.91(0.46,1.82)$ & $1.02(0.59,1.78)$ & 0.79 \\
\hline \multicolumn{7}{|l|}{ Driving $(\mathrm{Y} / \mathrm{N})^{\mathrm{b}}$} \\
\hline $\begin{array}{l}\text { Doesn't always use seatbelt (driver or } \\
\text { passenger) }\end{array}$ & 315 & $102(32.4)$ & $1.03(0.72,1.45)$ & $1.19(0.63,2.23)$ & $0.94(0.62,1.43)$ & 0.55 \\
\hline Texts/looks at phone while driving & 221 & $110(49.8)$ & $0.85(0.63,1.15)$ & $0.81(0.51,1.27)$ & $0.88(0.59,1.31)$ & 0.77 \\
\hline Drives without license (regularly) & 221 & $96(43.4)$ & $1.74(1.25,2.42)$ & $2.18(1.35,3.50)$ & $1.46(0.93,2.28)$ & 0.23 \\
\hline \multicolumn{7}{|l|}{ Delinquency/police encounters $(\mathrm{Y} / \mathrm{N})^{\mathrm{b}}$} \\
\hline Police encounters & 315 & $77(24.4)$ & $1.16(0.76,1.78)$ & $1.25(0.70,2.24)$ & $1.07(0.57,2.02)$ & 0.72 \\
\hline Any delinquent act & 315 & $221(70.2)$ & $0.97(0.83,1.13)$ & $1.09(0.90,1.32)$ & $0.88(0.69,1.11)$ & 0.15 \\
\hline Delinquency/police encounters (counts) & & median (25-75\%ile) & $\operatorname{IRR}(95 \% \mathrm{CI})^{\mathrm{a}}$ & Males IRR $(95 \% \mathrm{CI})^{\mathrm{a}}$ & Females IRR $(95 \% \mathrm{Cl})^{\mathrm{a}}$ & \\
\hline Police encounters & 315 & $0(0-0)$ & $1.56(0.91,2.70)$ & $2.10(0.97,4.54)$ & $1.10(0.51,2.38)$ & 0.24 \\
\hline $\begin{array}{l}\text { Delinquent acts: number of different } \\
\text { types of acts }\end{array}$ & 315 & $2(0-6)$ & $1.01(0.76,1.35)$ & $1.29(0.88,1.88)$ & $0.85(0.56,1.27)$ & 0.13 \\
\hline Delinquent acts: frequency of behaviors & 315 & $8(0-34)$ & $1.13(0.75,1.69)$ & $1.51(0.86,2.64)$ & $0.90(0.52,1.55)$ & 0.19 \\
\hline
\end{tabular}

childhood OP exposure was associated with mostly null associations with juvenile delinquency at age 16 years in CHAMACOS [36]. In the current study, we investigated how these associations manifest more broadly in risk-taking behavior as these children transition to adulthood.

We hypothesized that one of the primary pathways for associations of prenatal OP exposure with risk-taking behaviors is through associations with neurodevelopment. Previous studies, including CHAMACOS, report associations of prenatal DAPs with poorer cognition [2, $6,7]$, as well as behaviors related to $\operatorname{ADHD}[4,11,56]$. Suspected mechanisms underlying associations of lowlevel OPs (not high enough to inhibit acetylcholinesterase) with neurodevelopment include inhibition of axonal growth [57, 58], increased oxidative stress [59-61], and epigenetic modifications [62, 63]. However, as essentially all associations of DAP concentrations with risk-taking behaviors were null, examination of mediation by neurodevelopment was moot.
California accounts for about $25 \%$ of all U.S. agricultural pesticide use and in 2012, 9.2 million pounds of pesticides were applied in Monterey County, where Salinas is located [64]. Higher OP pesticide exposure has been shown in CHAMACOS, with women's urinary DAP concentrations averaging $40 \%$ higher, though within range, of those in the representative NHANES sample of U.S. women of child-bearing age [37]. These high exposures, coupled with adverse sociodemographic conditions in Salinas, including early life adversity, creates conditions that may place youth at risk for increased risk-taking behavior in adolescence/early adulthood. In the current study we did not find clear or consistent differences by pesticide exposure measures across childhood adversity (high vs. low ACEs) in CHAMACOS (Table 3).

Overall, low study power was the largest limitation of this study, especially in models stratified by sex or adversity. Many of the outcomes we assessed in relation to risk-taking behavior are serious outcomes, including substance use, unprotected sex, and delinquent behavior. 
Table 3 Adjusted $^{a}$ relative risk (RR) of risk-taking behaviors reported at 18 years per 10-fold increase in mean prenatal total urinary DAP concentrations ( $\mathrm{nmol} / \mathrm{gL}$ ) stratified by ACEs, subsetting on participants with ACEs $(n=309)$ and dichotomized as low ACEs (<3; $n=220)$ and high ACEs (3+; $n=89$ ), in the CHAMACOS study population, enrolled 1999-2000 in Salinas Valley, California

\begin{tabular}{|c|c|c|c|c|c|}
\hline Outcome & Total N & N (\%) with outcome & Low ACEs RR $(95 \% \mathrm{Cl})^{\mathrm{a}}$ & High ACEs RR $(95 \% \mathrm{Cl})^{\mathrm{a}}$ & $\begin{array}{l}p \text {-value for } \\
\text { interaction }\end{array}$ \\
\hline \multicolumn{6}{|l|}{ Substance Use $(\mathrm{Y} / \mathrm{N})^{\mathrm{b}}$} \\
\hline Very drunk in last 30 days & 308 & $28(9.1)$ & $0.63(0.20,4.04)$ & $1.11(0.36,3.40)$ & 0.50 \\
\hline Smoked/vaped nicotine in last 30 days & 309 & $26(8.4)$ & $1.41(0.55,3.60)$ & $2.49(0.95,6.54)$ & 0.43 \\
\hline Smoked/vaped marijuana in the past last 30 days & 309 & $75(24.3)$ & $1.16(0.65,2.07)$ & $0.96(0.51,1.79)$ & 0.65 \\
\hline \multicolumn{6}{|l|}{$\operatorname{Sex}(Y / N)^{b}$} \\
\hline Sex before age 16 & 305 & $47(15.4)$ & $1.52(0.78,2.94)$ & $0.81(0.26,2.56)$ & 0.35 \\
\hline Doesn't always use a condom & 305 & $69(22.6)$ & $1.00(0.55,1.80)$ & $0.87(0.43,1.77)$ & 0.77 \\
\hline \multicolumn{6}{|l|}{ Driving $(\mathrm{Y} / \mathrm{N})^{\mathrm{b}}$} \\
\hline Doesn't always use seatbelt (driver or passenger) & 309 & $98(31.7)$ & $0.87(0.55,1.37)$ & $1.15(0.62,2.15)$ & 0.49 \\
\hline Texts/looks at phone while driving & 215 & $106(49.3)$ & $0.81(0.55,1.18)$ & $0.88(0.54,1.42)$ & 0.78 \\
\hline Drives without license (regularly) & 215 & $91(42.3)$ & $1.74(1.09,2.75)$ & $1.61(0.98,2.65)$ & 0.83 \\
\hline \multicolumn{6}{|l|}{ Delinquency/police encounters $(\mathrm{Y} / \mathrm{N})^{\mathrm{b}}$} \\
\hline Police encounters & 309 & $75(24.3)$ & $1.10(0.59,2.06)$ & $1.22(0.69,2.15)$ & 0.81 \\
\hline Any delinquent act & 309 & $217(70.2)$ & $1.01(0.83,1.24)$ & $0.87(0.67,1.12)$ & 0.34 \\
\hline Delinquency/police encounters (counts) ${ }^{c}$ & & median (25-75\%ile) & Low ACEs IRR $(95 \% \mathrm{CI})^{\mathrm{a}}$ & High ACEs IRR $\left(95 \%\right.$ CI) ${ }^{\mathrm{a}}$ & \\
\hline Police encounters & 309 & $0(0-0)$ & $1.39(0.69,2.83)$ & $2.53(1.07,6.02)$ & 0.30 \\
\hline $\begin{array}{l}\text { Delinquent acts: number of different types of } \\
\text { acts }\end{array}$ & 309 & $2(0-6)$ & $1.10(0.77,1.56)$ & $0.98(0.62,1.56)$ & 0.71 \\
\hline Delinquent acts: frequency of behaviors & 309 & $8(0-34)$ & $1.76(1.06,2.92)$ & $0.72(0.36,1.45)$ & 0.04 \\
\hline
\end{tabular}

The importance of investigating these associations cannot be overstated, given the pervasiveness of pesticide exposures and the serious nature of these outcomes. Further study of these associations in larger samples should be undertaken.

Another limitation of this study concerns exposure assessment. DAPs are non-specific metabolites and cannot be attributed to any single OP pesticide [65]. In addition, OPs are rapidly metabolized in the body [66], making exposure measurement error a central concern. We were able to offset this limitation somewhat with two pregnancy measures. And while non-differential measurement error could have explained the null associations found in this study, we have reported associations of maternal DAP metabolite concentrations with several developmental outcomes in CHAMACOS $[2,4,5,8,11]$.

We did not investigate associations of postnatal OP exposure with high-risk behavior. While there was certainly postnatal OP exposure in this community living in proximity to agriculture, associations of neurodevelopment with early childhood DAP exposure has been shown to be weaker that prenatal exposure in
CHAMACOS and other cohorts, as previously reported $[2,4,12]$. We therefore focused on prenatal exposure for the current analysis. However, given that neurodevelopment continues into early adulthood, it will be important to investigate associations with postnatal exposure throughout childhood and adolescence with these outcomes in future studies.

There were also notable strengths of this study. CHAMACOS is a prospective cohort recruited during pregnancy with high exposure to pesticides and adversity. We were able to take repeated measures of exposure during pregnancy, a critical window of exposure for brain development and therefore a potentially important window of exposure with respect to high-risk behavior. We also frequently followed up CHAMACOS participants with detailed outcome assessment including information about risk taking behaviors in youth.

\section{Conclusions}

In summary, we did not observe associations between prenatal OP exposure and risk-taking behaviors in adolescence/early adulthood in the CHAMACOS 
population. Larger studies may be needed to examine the potentially subtle associations of OPs with these risk-taking behaviors. This research is especially important given the gravity of these outcomes and the high prevalence of pesticide exposure in the population.

\section{Abbreviations}

ADHD: Attention deficit hyperactivity disorder; CES-D: Center for Epidemiologic Studies Depression Scale; CHAMACOS: Center for the Health Assessment of Mothers and Children of Salinas; Cl: Confidence interval; DAP: Dialkyl phosphate; DE: Diethyl phosphate; DM: Dimethyl phosphate; HOME: Home Observation for Measurement of the Environment; OP: Organophosphate; RR: Relative risk; YRBS: Youth Risk Behavior Surveillance.

\section{Supplementary Information}

The online version contains supplementary material available at https://doi. org/10.1186/s12940-021-00822-y.

\section{Additional file 1. \\ Additional file 2. \\ Additional file 3. \\ Additional file 4.}

\section{Acknowledgements}

We thank the CHAMACOS staff, students, community partners, and participants and families who made this study possible, as well as the biorepository staff for their assistance in specimen management.

\section{Authors' contributions}

Sharon K. Sagiv: Substantial contributions to analysis and interpretation of data; drafted sections and critical review of entire manuscript. Stephen Rauch: Substantial contributions to data analysis; drafted sections and critical review of manuscript. Katherine R. Kogut: Substantial contributions to acquisition of data; contributions to analysis and interpretation of data; drafted sections and critical review of manuscript. Carly Hyland: Contributions to analysis and interpretation of data; drafted sections and critical review of manuscript. Robert B. Gunier: Substantial contributions to analysis and interpretation of data, including exposure and outcome data; critical review of manuscript. Ana M. Mora: Substantial contributions to analysis and interpretation of data; critical review of entire manuscript. Asa Bradman: Substantial contributions to conception and design and acquisition of data assessing maternal exposure to pesticides. Coordinated the urine sample collection and interfaced with laboratories to accomplish measurement of DAP metabolites in maternal urine; critical review of manuscript. Julianna Deardorff: Substantial contributions to conception and design; significant contributions to interpretation of data, particularly outcome data; critical review of manuscript. Brenda Eskenazi: Substantial contributions to conception and design, acquisition of data, or analysis and interpretation of data; drafted manuscript. The authors read and approved the final manuscript.

\section{Funding}

This publication was made possible by research supported by grant numbers: RD 82670901, RD 83171001, and RD 83451301 from the U.S. Environmental Protection Agency (US EPA); and P01 ES009605, R01 ES015572, R24 ES028529, R01 ES026994 from NIEHS; and R01 DA035300 from NIDA. The contents of this publication are solely the authors' responsibility and do not necessarily represent the official views of $\mathrm{NIH}$, US EPA, or the Centers for Disease Control and Prevention.

\section{Availability of data and materials}

The datasets generated during and/or analyzed during the current study are not publicly available due to protection of personal identifiers and the sensitive nature of these data, but are available from the corresponding author on reasonable request.

\section{Declarations}

\section{Ethics approval and consent to participate}

Written informed consent was obtained from mothers upon enrollment and follow up; children provided verbal assent starting at age 7, written assent starting at age 12, and full written consent at age 18 . All activities were approved by the University of California, Berkeley Office for the Protection of Human Subjects.

\section{Consent for publication}

Not applicable.

\section{Competing interests}

Dr. Asa Bradman is a volunteer member of the Board of Trustees for The Organic Center, a non-profit organization addressing scientific issues about organic food and agriculture, and is a member of the USDA National Organic Standards Board. The authors have no other conflicts of interest relevant to this article to disclose.

\section{Author details}

${ }^{1}$ Center for Environmental Research and Community Health (CERCH), Schoo of Public Health, University of California, 1995 University Avenue, Suite 265, Berkeley, CA 94720, USA. ² Department of Public Health, University of California, Merced, CA, USA.

Received: 17 September 2021 Accepted: 21 December 2021

Published online: 10 January 2022

\section{References}

1. Coker E, Gunier R, Bradman A, Harley K, Kogut K, Molitor J, Eskenazi B. Association between Pesticide Profiles Used on Agricultural Fields near Maternal Residences during Pregnancy and IQ at Age 7 Years. Int J Environ Res Public Health. 2017;14(5):506.

2. Bouchard MF, Chevrier J, Harley KG, Kogut K, Vedar M, Calderon N, et al. Prenatal exposure to organophosphate pesticides and IQ in 7-year-old children. Environ Health Perspect. 2011;119(8):1189-95.

3. Gunier RB, Bradman A, Harley KG, Kogut K, Eskenazi B. Prenatal residential proximity to agricultural pesticide use and IQ in 7-year-old children. Environ Health Perspect. 2017;125(5):057002.

4. Marks AR, Harley K, Bradman A, Kogut K, Barr DB, Johnson C, et al. Organophosphate pesticide exposure and attention in young MexicanAmerican children: the CHAMACOS study. Environ Health Perspect. 2010;118(12):1768-74.

5. Sagiv SK, Harris MH, Gunier RB, Kogut KR, Harley KG, Deardorff J, et al. Prenatal organophosphate pesticide exposure and traits related to autism Spectrum disorders in a population living in proximity to agriculture. Environ Health Perspect. 2018;126(4):047012.

6. Engel SM, Wetmur J, Chen J, Zhu C, Barr DB, Canfield RL, et al. Prenatal exposure to organophosphates, paraoxonase 1, and cognitive development in childhood. Environ Health Perspect. 2011;119(8):1182-8.

7. Engel SM, Berkowitz GS, Barr DB, Teitelbaum SL, Siskind J, Meisel SJ, et al. Prenatal organophosphate metabolite and organochlorine levels and performance on the Brazelton neonatal behavioral assessment scale in a multiethnic pregnancy cohort. Am J Epidemiol. 2007;165(12):1397-404.

8. Eskenazi B, Marks AR, Bradman A, Harley K, Barr DB, Johnson C, et al. Organophosphate pesticide exposure and neurodevelopment in young Mexican-American children. Environ Health Perspect. 2007;115(5):792-8.

9. Rauh V, Arunajadai S, Horton M, Perera F, Hoepner L, Barr DB, et al. Seven-year neurodevelopmental scores and prenatal exposure to chlorpyrifos, a common agricultural pesticide. Environ Health Perspect. 2011;119(8):1196-201.

10. Rauh VA, Garfinkel R, Perera FP, Andrews HF, Hoepner L, Barr DB, et al. Impact of prenatal chlorpyrifos exposure on neurodevelopment in the first 3 years of life among inner-city children. Pediatrics. 2006;118(6):e1845-59.

11. Sagiv SK, Kogut K, Harley K, Bradman A, Morga N, Eskenazi B. Gestational exposure to organophosphate pesticides and longitudinally assessed 
behaviors related to ADHD and executive function. Am J Epidemiol. 2021; In press.

12. Sapbamrer R, Hongsibsong S. Effects of prenatal and postnatal exposure to organophosphate pesticides on child neurodevelopment in different age groups: a systematic review. Environ Sci Pollut Res Int 2019;26(18):18267-90.

13. White JL, Moffitt TE, Caspi A, Bartusch DJ, Needles DJ, Stouthamer-Loeber M. Measuring impulsivity and examining its relationship to delinquency. J Abnorm Psychol. 1994;103(2):192-205.

14. HerrenkohI TI, Maguin E, Hill KG, Hawkins JD, Abbott RD, Catalano RF. Developmental risk factors for youth violence. J Adolesc Health. 2000;26(3):176-86.

15. Barkley RA. Driving impairments in teens and adults with attentiondeficit/hyperactivity disorder. Psychiatr Clin North Am. 2004;27(2):233-60.

16. Dalsgaard S, Mortensen PB, Frydenberg M, Thomsen PH. Long-term criminal outcome of children with attention deficit hyperactivity disorder. Crim Behav Ment Health. 2013;23(2):86-98.

17. Satterfield JH, Faller KJ, Crinella FM, Schell AM, Swanson JM, Homer LD. A 30-year prospective follow-up study of hyperactive boys with conduct problems: adult criminality. J Am Acad Child Adolesc Psychiatry. 2007:46(5):601-10.

18. Lundström S, Forsman M, Larsson H, Kerekes N, Serlachius E, Långström N, Lichtenstein P. Childhood neurodevelopmental disorders and violent criminality: a sibling control study. J Autism Dev Disord. 2014:44(11):2707-16.

19. Molina BS, Pelham WE Jr. Childhood predictors of adolescent substance use in a longitudinal study of children with ADHD. J Abnorm Psychol. 2003;112(3):497-507.

20. Gittelman R, Mannuzza S, Shenker R, Bonagura N. Hyperactive boys almost grown up. I. Psychiatric status. Arch Gen Psychiatry. 1985:42(10):937-47.

21. Kandel E, Mednick SA, Kirkegaard-Sorensen L, Hutchings B, Knop J, Rosenberg $\mathrm{R}$, et al. IQ as a protective factor for subjects at high risk for antisocial behavior. J Consult Clin Psychol. 1988;56(2):224-6.

22. Lynam D, Moffitt T, Stouthamer-Loeber M. Explaining the relation between IQ and delinquency: class, race, test motivation, school failure, or self-control? J Abnorm Psychol. 1993;102(2):187-96.

23. Dietrich KN, Ris MD, Succop PA, Berger OG, Bornschein RL. Early exposure to lead and juvenile delinquency. Neurotoxicol Teratol. 2001;23(6):511-8.

24. McCall PL, Land KC. Trends in environmental lead exposure and troubled youth, 1960-1995: an age-period-cohort-characteristic analysis. Soc Sci Res. 2004;33(2):339-59.

25. Mielke HW, Zahran S. The urban rise and fall of air lead (Pb) and the latent surge and retreat of societal violence. Environ Int. 2012:43:48-55.

26. Needleman HL, McFarland C, Ness RB, Fienberg SE, Tobin MJ. Bone lead levels in adjudicated delinquents. A case control study. Neurotoxicol Teratol. 2002;24(6):711-7.

27. Needleman HL, Riess JA, Tobin MJ, Biesecker GE, Greenhouse JB. Bone lead levels and delinquent behavior. JAMA. 1996;275(5):363-9.

28. Nevin R. How lead exposure relates to temporal changes in IQ, violent crime, and unwed pregnancy. Environ Res. 2000;83(1):1-22.

29. Nevin R. Understanding international crime trends: the legacy of preschool lead exposure. Environ Res. 2007:104(3):315-36.

30. Reyes JW. Environmental Policy as Social Policy? The Impact of Childhood Lead Exposure on Crime. In: National Bureau of Economic Research; 2007.

31. Stretesky PB, Lynch MJ. The relationship between lead and crime. J Health Soc Behav. 2004:45(2):214-29.

32. Wright JP, Dietrich KN, Ris MD, Hornung RW, Wessel SD, Lanphear BP, et al. Association of Prenatal and Childhood Blood Lead Concentrations with criminal arrests in early adulthood. PLoS Med. 2008;5(5):e101.

33. Haynes EN, Chen A, Ryan P, Succop P, Wright J, Dietrich KN. Exposure to airborne metals and particulate matter and risk for youth adjudicated for criminal activity. Environ Res. 2011;111(8):1243-8.

34. Lotfipour S, Ferguson E, Leonard G, Miettunen J, Perron M, Pike GB, et al. Maternal cigarette smoking during pregnancy predicts drug use via externalizing behavior in two community-based samples of adolescents. Addiction. 2014:109(10):1718-29.

35. Mohai P, Kweon B, Lee S, Ard K. Air pollution around schools is linked to poorer student health and academic performance. Health Aff. 2011:30(5):852-62.
36. Vernet C, Johnson M, Kogut K, Hyland C, Deardorff J, Bradman A, et al. Organophosphate pesticide exposure during pregnancy and childhood and onset of juvenile delinquency by age 16 years: the CHAMACOS cohort. Environ Res. 2021;197:111055.

37. Bradman A, Eskenazi B, Barr D, Bravo R, Castorina R, Chevrier J, et al. Organophosphate urinary metabolite levels during pregnancy and after delivery in women living in an agricultural community. Environ Health Perspect. 2005;113(12):1802-7.

38. Bravo R, Driskell WJ, Whitehead RD Jr, Needham LL, Barr DB. Quantitation of dialkyl phosphate metabolites of organophosphate pesticides in human urine using GC-MS-MS with isotopic internal standards. J Anal Toxicol. 2002;26(5):245-52.

39. Elkins HB, Pagnotto LD. The specific gravity adjustment in urinalysis. Arch Environ Health. 1969;18(6):996-1001.

40. Kann L, McManus T, Harris WA, Shanklin SL, Flint KH, Queen B, et al. Youth risk behavior surveillance - United States, 2017. MMWR Surveill Summ. 2018;67(8):1-114.

41. Methodological overview of a multisite HIV prevention trial for populations at risk for HIV. NIMH Multisite HIV Prevention Trial. AIDS. 1997;11(Suppl 2):S1-11.

42. Deutsch AR. "A Test of a Conceptual Model of Sexual Self-Concept and its Relation to Other Dimensions of Sexuality" (2012). Theses, Dissertations, and Student Research: Department of Psychology. 48. In.; 2012.

43. Barkley RA, Murphy KR, Kwasnik D. Motor vehicle driving competencies and risks in teens and young adults with attention deficit hyperactivity disorder. Pediatrics. 1996;98(6 Pt 1):1089-95.

44. Elliott DS, Huizinga D. Social class and delinquent behavior in a National Youth Panel - 1976-1980. Criminology. 1983;21:149-77.

45. Hinshaw SP, Owens EB, Sami N, Fargeon S. Prospective follow-up of girls with attention-deficit/hyperactivity disorder into adolescence: evidence for continuing cross-domain impairment. J Consult Clin Psychol. 2006;74(3):489-99.

46. Van Hulle CA, Rodgers JL, D'Onofrio BM, Waldman ID, Lahey BB. Sex differences in the causes of self-reported adolescent delinquency. J Abnorm Psychol. 2007;1 16(2):236-48.

47. Centers for Disease Control and Prevention: Adverse Childhood Experiences (ACEs). https://www.cdc.gov/violenceprevention/childabuseandne glect/acestudy/index.html. Accessed 1 Jan 2020

48. Middlebrooks JS, Audage NC. The effects of childhood stress on health across the lifespan. Atlanta: Centers for Disease Control and Prevention. In; 2008.

49. Dunn LM. Examiner's manual for the Peabody picture vocabulary test. 3rd ed. Circle Pines: American Guidance Service; 1997.

50. Dunn LM, Padilla ER, Lugo DE, L.M. D. Test de Vocabulario en Imagenes Peabody: Adaptacion Hispanoamericana (Peabody picture vocabulary test: Hispanic-American adaptation). Circle Pines: American Guidance Service; 1986.

51. Radoff LS. The CES-D scale: a self-report depression scale for research in the general population. Appl Psychol Meas. 1977;1 (3):85-401.

52. Caldwell B, Bradley R. Home observation for measurement of the environment - revised edition. Little Rock: University of Arkansas; 1984.

53. Valeri L, Vanderweele TJ. Mediation analysis allowing for exposuremediator interactions and causal interpretation: theoretical assumptions and implementation with SAS and SPSS macros. Psychol Methods. 2013;18(2):137-50

54. Barker DJ. The origins of the developmental origins theory. J Intern Med. 2007:261(5):412-7.

55. Heindel JJ, Vandenberg LN. Developmental origins of health and disease: a paradigm for understanding disease cause and prevention. Curr Opin Pediatr. 2015;27(2):248-53.

56. Bouchard MF, Bellinger DC, Wright RO, Weisskopf MG. Attention-deficit/ hyperactivity disorder and urinary metabolites of organophosphate pesticides. Pediatrics. 2010;125(6):e1270-7.

57. Howard AS, Bucelli R, Jett DA, Bruun D, Yang D, Lein PJ. Chlorpyrifos exerts opposing effects on axonal and dendritic growth in primary neuronal cultures. Toxicol Appl Pharmacol. 2005;207(2):112-24.

58. Yang D, Howard A, Bruun D, Ajua-Alemanj M, Pickart C, Lein PJ. Chlorpyrifos and chlorpyrifos-oxon inhibit axonal growth by interfering with the morphogenic activity of acetylcholinesterase. Toxicol Appl Pharmacol. 2008;228(1):32-41. 
59. Crumpton TL, Seidler FJ, Slotkin TA. Is oxidative stress involved in the developmental neurotoxicity of chlorpyrifos? Brain Res Dev Brain Res. 2000;121(2):189-95.

60. Giordano G, Afsharinejad Z, Guizzetti M, Vitalone A, Kavanagh TJ, Costa LG. Organophosphorus insecticides chlorpyrifos and diazinon and oxidative stress in neuronal cells in a genetic model of glutathione deficiency. Toxicol Appl Pharmacol. 2007;219(2-3):181-9.

61. Slotkin TA, Seidler FJ. Oxidative stress from diverse developmental neurotoxicants: antioxidants protect against lipid peroxidation without preventing cell loss. Neurotoxicol Teratol. 2010;32(2):124-31.

62. Kim HY, Wegner SH, Van Ness KP, Park JJ, Pacheco SE, Workman T, et al. Differential epigenetic effects of chlorpyrifos and arsenic in proliferating and differentiating human neural progenitor cells. Reprod Toxicol. 2016;65:212-23.

63. Shin HS, Seo JH, Jeong SH, Park SW, Park Yl, Son SW, et al. Effect on the H19 gene methylation of sperm and organs of offspring after chlorpyrifos-methyl exposure during organogenesis period. Environ Toxicol. 2015;30(12):1355-63.

64. California Department of Pesticide Regulation. Pesticide Use Reporting Data for 2012. Sacramento; 2014

65. US EPA. Revised Cumulative Risk Assessment of Organophosphorus Pesticides. Washington, DC: Office of Pesticide Programs, U.S. Environmental Protection Agency; 2002.

66. Bradman A, Kogut K, Eisen EA, Jewell NP, Quiros-Alcala L, Castorina R, et al. Variability of organophosphorous pesticide metabolite levels in spot and 24-hr urine samples collected from young children during 1 week. Environ Health Perspect. 2013;121(1):118-24.

\section{Publisher's Note}

Springer Nature remains neutral with regard to jurisdictional claims in published maps and institutional affiliations.

- fast, convenient online submission

- thorough peer review by experienced researchers in your field

- rapid publication on acceptance

- support for research data, including large and complex data types

- gold Open Access which fosters wider collaboration and increased citations

- maximum visibility for your research: over $100 \mathrm{M}$ website views per year

At BMC, research is always in progress.

Learn more biomedcentral.com/submissions 